\title{
CONTROLADORIA APLICADA NAS MICRO E PEQUENAS EMPRESAS COMO FERRAMENTA DE GESTÃO
}

\section{ARTIGO ORIGINAL}

BORGES, Pedro Felipe Mendes ${ }^{1}$, SANTOS, Ana Paula de Lira dos², ROBERTO, José Carlos Alves ${ }^{3}$, SERRA, Meg Rocha da Cunha ${ }^{4}$, LOPES, Nelânia Ferreira ${ }^{5}$

BORGES, Pedro Felipe Mendes. Et al. Controladoria aplicada nas micro e pequenas empresas como ferramenta de gestão. Revista Científica Multidisciplinar Núcleo do Conhecimento. Ano. 06, Ed. 11, Vol. 05, pp. 87-105. Novembro 2021. ISSN: 2448-0959, Link de acesso: https://www.nucleodoconhecimento.com.br/contabilidade/controladoria, $\quad$ DOI: 10.32749/nucleodoconhecimento.com.br/contabilidade/controladoria

\section{RESUMO}

Este artigo tem por objetivo demonstrar as dificuldades rotineiras presentes dentro das Micro e Pequenas Empresas (MPEs) e discutir sobre a contribuição da Controladoria como uma ferramenta de gestão. Entretanto, para o aprofundamento do assunto, levantou-se a seguinte pergunta norteadora: a controladoria pode ser usada como uma ferramenta de gestão para melhorar o desempenho econômico e organizacional das MPEs? Dessa maneira, tem como finalidade demonstrar o quão benéfica a controladoria pode ser para essas pequenas organizações. A metodologia utilizada para a criação deste estudo foi a pesquisa bibliográfica. Foram revisitados conteúdos já publicados, tais como livros, artigos, revistas, jornais e mídias agregadoras ao assunto. Referente aos resultados encontrados, destaca-se

\footnotetext{
${ }^{1}$ Graduando do curso de Contabilidade.

${ }^{2}$ Graduando do curso de Contabilidade.

${ }^{3}$ Orientador. Mestre em Engenharia de produção. Especialista Logística empresarial. Graduado em Administração com Ênfase em Marketing.

${ }^{4}$ Orientadora. Mestra em Engenharia de Processos Industriais pela UFPA, especialista em Controladoria e Auditoria Contábil pelo Ciesa, Graduada em Ciências Contábeis pelo Centro Universitário do Norte. Graduada em Ciências Econômicas pelo Centro Universitário do Norte.

${ }^{5}$ Orientadora. Especialista em Auditoria Contábil, Financeira e Tributaria e Graduada em Ciências Contábeis.
}

RC: 100868

Link de acesso: 
o dinamismo da controladoria e a versatilidade de suas funções, de forma que múltiplos âmbitos das MPEs foram contemplados pelas ramificações dos seus conhecimentos. Pôde-se observar a sua aplicação em diversos setores, como o de sistema de informação, financeiro, administrativo e nas tomadas de decisões. Contudo, comprovou-se que a controladoria é útil como uma ferramenta de gestão, pois seus benefícios são significativos à projeção de melhor resultados nos âmbitos geral e primordial como auxílio aos processos gerenciais.

Palavras-chave: Controladoria, Gestão, Micro, Pequenas Empresas.

\section{INTRODUÇÃO}

As Micro e Pequenas Empresas (MPEs) são empresas de pequeno porte, sendo muito importantes para a economia no Brasil, pois, segundo o Sebrae (2021), são líderes na geração de novos empregos e distribuição de renda. Entretanto, a alta concorrência e as dificuldades de se manterem firmes no mercado é um grande empecilho enfrentado por essas pequenas companhias. Além das dificuldades naturais referentes ao mercado, as MPEs possuem outras diversas questões organizacionais internas que prejudicam a sua performance, sendo a falta de uma gestão geral e eficiente a maior delas. O mau uso dos recursos financeiros, falta de planejamento e um sistema de informação ineficaz são alguns dos fatores principais que costumam levá-las à falência e fecharem suas portas.

Sendo assim, esta pesquisa tem como pergunta norteadora: a controladoria pode ser usada como uma ferramenta de gestão para melhorar o desempenho econômico das MPEs? A controladoria é uma ferramenta advinda da contabilidade e tem como função principal conhecer a empresa, suas dificuldades e elaborar novas soluções para ela, com o objetivo de mantê-la com boa saúde e impulsioná-la para obter melhores resultados (MULER; BEUREN, 2010). Portanto, esta pesquisa tem como objetivo geral demonstrar o quão benéfica a controladoria pode ser quando utilizada como ferramenta de gestão, detalhando, de forma clara e objetiva, toda a sua 
versatilidade e importância na aquisição de melhores resultados e tomadas de boas decisões dentro das MPEs.

Quanto à natureza da pesquisa, o método empregado foi o de pesquisa básica, pois foram utilizados os conteúdos já existentes, criando um raciocínio com base neles. Sobre os fins, o mecanismo escolhido foi o de pesquisa descritiva, de maneira que as particularidades do assunto foram usadas como ponto central para a realização das análises relacionadas ao tema. Referente aos meios, foi utilizado o método bibliográfico, de forma que livros, revistas, artigos e diversas outras mídias pertinentes ao assunto foram exploradas para o desenvolvimento do trabalho.

\section{FUNDAMENTAÇÃO TEÓRICA}

No decorrer desta pesquisa, serão apresentados conhecimentos teóricos que terão embasamentos em trabalhos sobre o assunto já publicados. Dessa maneira, autores que já contribuíram para o desenvolvimento do assunto serão utilizados para validar a complementação e contribuição do conteúdo atual aqui discutido. Neste processo de revisitação, é crucial que sejam usadas sustentações teóricas de autores que tenham domínio sobre o que está sendo discutido, sendo, geralmente, doutores ou algum especialista no assunto. Dessa forma, o conteúdo desenvolvido pelo autor do artigo em criação será contraposto e comparado com o conteúdo já existente, a fim de validar e complementar a nova pesquisa produzida (SOARES et al., 2018). Portanto, todo o material produzido nesta pesquisa virá deste mecanismo, com o propósito de fortalecer uma discussão mais clara e de forma mais sólida.

\subsection{DEFINIÇÃO DE MICRO E PEQUENAS EMPRESAS}

Uma forma simples e básica de entender o que é uma Micro e Pequena empresa é imaginando o seu contrário: as grandes empresas também conhecidas como empresas de grande porte. As empresas de grande porte, ou grandes empresas, têm como característica principal a alta quantidade de funcionários e um elevado faturamento anual. Diferentemente do seu oposto, menciona-se que as Micro e 
Pequenas empresas (MPEs) possuem um quadro de funcionários menor e um faturamento modesto também, o que, conforme explica o Portal da Indústria (2021), as MPEs são definidas, basicamente, conforme dois critérios fundamentais, que são o valor do seu faturamento anual e a quantidade de seus funcionários, conforme requisitos abaixo:

- Microempresa - Faturamento anual máximo de $\mathrm{R} \$ 360.000,00$, podendo ter 9 funcionários no setor de comércio ou até 19 funcionários no setor industrial;

- Pequenas Empresas - Faturamento anual máximo de $\mathrm{R} \$ 4.800 .000,00$, podendo ter de 10 a 49 funcionários no setor de comércio ou até 20 a 99 funcionários no setor industrial.

Além disso, é necessário frisar a importância da Lei Geral (BRASIL 2006), que surgiu como grande avanço em termos de benefícios para as Micro e Pequenas empresas, pois simplificou e desburocratizou o processo de arrecadação de impostos para essa categoria de empresa, proporcionando uma forma de recolhimento mais justa, unificada e diferenciada. Dessa maneira, segundo o Sebrae (2014), as MPEs têm como objetivo fundamental aumentar a geração de empregos, incentivar o comércio no Brasil, fortalecer a economia, além de gerar maior distribuição de renda e a diminuição da informalidade no país. Devido a isso, as MPEs representam 99\% das empresas no Brasil e configuram, nesse sentido, uma das organizações que mais geram empregos também.

\subsection{EMPREENDEDORISMO}

O surgimento das micro e pequenas empresas está inteiramente ligado à prática do empreendedorismo, pois é por meio dessas iniciativas que muitas das empresas inovadoras e de sucesso surgem. Empreender está ligado ao fato de arriscar, planejar e criar algo, trazendo novas soluções para problemas que ainda não foram solucionados ou, ainda, caso detectado, melhora-se algo que já existe. Independentemente do tipo de empresa ou da vantagem que ela tenha, as dificuldades de conquistar e permanecer com uma fatia participativa dentro do 
mercado ainda será uma realidade, logo, possuir um estilo empreendedor é essencial, pois o mercado muda a todo instante e ser inovador é primordial. Segundo Kumar e Ali (2010), empreender é ver a partir da desordem, inconsistência e problemas não solucionados a iniciativa e a possibilidade de vencer e prosperar.

Não é incorreto afirmar que o ser humano, desde a sua origem, é um empreendedor nato, pois, seguindo o pressuposto que empreender é melhorar ou criar soluções para as facilidades humanas, é algo que faz muito sentido. Dessa maneira, identificar e incentivar as qualidades empreendedoras naturais de cada ser humano é algo vital, pois, aplicando isso de uma forma mais educacional, será possível introduzir as novas inovações, bem como investir no crescimento profissional e geração de empregos (BRACHT; WERLANG, 2015). De fato, para abrir uma empresa é necessário seguir e superar vários desafios. Entretanto, ficar antenado ao mercado e se manter atualizado é uma tarefa constante, além de não esquecer o que realmente importa e o que motivou a construção da organização. Empreender, segundo Dolabela (2010), é trabalhar com o que há inicialmente na mente, transformando isso em realidade e, consequentemente, em soluções e riquezas.

\subsection{DIFICULDADES ENCONTRADAS NA GESTÃO}

As MPE's são a maioria quando se fala na propagação de empresas no Brasil, consequentemente, isso reflete em uma maior participação dentro do PIB nacional e, também, nos números expressivos de oportunidades de empregos e renda no país. Entretanto, não é fácil permanecer ativo e firme dentro dessa selva que é o mercado empresarial, pois, ao mesmo tempo que a cada momento novas empresas surgem, em contrapartida, muitas também fecham. São inúmeras as condições que levam as MPEs a terem dificuldades em suas gestões. Entretanto, segundo o Sebrae (2016), as causas que mais encaminham a morte precoce das pequenas empresas são, sem dúvidas, um planejamento ruim, inconsistência nas operações de marketing, além de um controle não eficaz de custos e do caixa da organização.

RC: 100868

Link de acesso:

https://www.nucleodoconhecimento.com.br/contabilidade/controladoria 
Além disso, outra questão que pode ser apontada sobre a mortalidade das Micro e Pequenas empresas é, sem dúvidas, o excesso de burocracia que passam a enfrentar desde o processo da sua abertura, como as altas cargas tributárias impostas pelo governo, o difícil acesso às tecnologias de ponta, como, também, as dificuldades de aquisição de crédito e de outros serviços financeiros quando necessários. Sendo assim, fica evidente que abrir e gerenciar uma Micro e Pequena empresa no Brasil não é uma tarefa fácil, de modo que cabe a cada organização buscar meios e formas para solucionar esses obstáculos que persistem no mercado.

\subsection{CONCEITO DE CONTROLADORIA}

A controladoria é uma ferramenta advinda da contabilidade e tem como função desenvolver e aplicar métodos de maior controle para melhorar o desempenho das organizações. Dessa forma, conforme explicam Oliveira, Perez Jr. e Silva (2011), a controladoria pode ser vista ou facilmente explicada como um tipo de divisão responsável por planejar, aplicar e unificar as informações gerais da instituição, usando destas para prover melhores resultados. Com a globalização e a intensidade da competitividade das empresas por uma fatia do mercado, usufruir de uma boa controladoria é um passo à frente não apenas para as grandes empresas, mas também para aquelas consideradas como pequenas também, que é o caso das micro e pequenas empresas.

Sobre a finalidade da controladoria, Nascimento e Reginato (2010) afirmam que a controladoria busca analisar e entender de forma profunda as características que envolvem os processos decisórios e o estilo de gestão no momento das tomadas de decisões. Já se tratando de controles mais internos, a controladoria visa unir departamentos e melhorar o trabalho em conjunto entre eles. Segundo Fortes e Silva (2016), os benefícios dessa vertente da contabilidade estão sendo usufruídos por muitas organizações em todo o mundo, pois esses conhecimentos favorecem não apenas a boa gestão, mas também fornecem uma maior transparência e segurança nos processos diários, principalmente se tratando de investimentos, sendo que, quanto maior for o nível de segurança, melhor.

RC: 100868

Link de acesso:

https://www.nucleodoconhecimento.com.br/contabilidade/controladoria 
Portanto, pode-se concluir que a controladoria é um conjunto de utilidades que, quando aplicado da forma correta, pode prover benefícios para toda a massa empresária, tendo a proposta de alcançar e melhorar os processos internos, trazendo rentabilidade e controle de alta qualidade para todas as organizações que a utilizarem.

\subsubsection{CONTROLADORIA APLICADA ÀS MPE'S}

Aplicar controladoria em uma empresa de pequeno porte, diante de suas características e necessidades constantes, não é uma tarefa fácil, pois, por serem pequenas, muitas dessas empresas consideram esse tipo de gestão algo caro e inacessível. Não é incorreto afirmar que processos como controladoria e até mesmo sistemas de auditoria, geralmente, são vistos como ferramentas mais voltadas para grandes empresas e não para as pequenas. Entretanto, desenvolver processos de controladoria em MPEs não é algo tão inacessível quanto aparenta, conforme explica Souza (2008), pois um sistema de controladoria apenas poderá ser implantado com eficiência em um micro ou pequena empresa se ela estiver disposta a iniciar um planejamento de desenvolvimento interno, porém qualquer empresa pode aplicar essa ferramenta, independente da organização que tenha. Basta empregar as ferramentas corretas.

A controladoria aplicada nas micro e pequena empresas tem como papel principal assegurar e prover melhores desempenhos para as organizações, sendo assim, implica a aplicação de um planejamento de controle eficaz após a coleta de informações, sendo que estas serão peças chaves na administração e nas futuras tomadas de decisões (ELEUTÉRIO, 2014). Conforme complementam Nascimento e Reginato (2013), o objetivo da controladoria é o de fornecer uma gestão mais limpa e sólida, apoiando o processo de decisão, tendo em vista que ela usa de forma categórica as informações e facilita os processos operacionais. É importante deixar claro que a controladoria não se aplica apenas aos casos burocráticos e de altos setores dentro das empresas. Ela promove melhorias desde as funções e setores 
básicos até os lugares mais altos da pirâmide organizacional, trazendo múltiplos benefícios para a companhia como um todo.

\subsubsection{CONTROLLER}

Antes de partir para o uso das ferramentas, é necessário evidenciar a importância do profissional de controladoria, também conhecido como controller. O controller é um profissional multitarefas, pois tem conhecimentos nas áreas de administração, contábil e financeira, cujo a gente é, geralmente, responsável pela gestão financeira e orçamentária da empresa. A palavra controller, como o próprio nome sugere, advém da palavra controle, que, segundo Souza (2010), significa "formas para se chegar em um fim, buscando sempre um planejamento para se obter o verdadeiro controle". O controller, geralmente, participa da organização administrativa da entidade, sendo que, com sua gestão, pode auxiliar os demais gestores na organização dos setores, utilizando o sistema de informação de forma mais assertiva, fazendo com que a comunicação entre eles seja bem mais fluida, rápida e objetiva.

Dessa forma, com o uso inteligente das informações, o controller auxilia nas tomadas de decisões (SCHMIDT; SANTOS; MARTINS, 2014). É importante frisar que o controller não é somente um gerador de relatórios com números e análises, mas sim um profissional completo, pois seus conhecimentos, que vão desde a administração, contabilidade e recursos humanos, por exemplo, são muito pertinentes ao gerir um negócio. As empresas de médio e pequeno porte, que é o caso das MPEs, vem a cada dia reconhecendo a necessidade desses profissionais e contratando esses especialistas. Por fim, fica evidente que o controller é um profissional gerencial e analítico, pois é ele que traz e usa de forma eficaz as informações da empresa, conforme explicam Oliveira, Perez Júnior e Silva (2011), afirmando que o controller é o agente que tem total capacidade para assessorar os executivos principais, além dos gestores na definição de estratégias e propostas assertivas para $o$ crescimento.

RC: 100868

Link de acesso:

https://www.nucleodoconhecimento.com.br/contabilidade/controladoria 


\subsection{FERRAMENTAS DE CONTROLE E GESTÃO}

As ferramentas de controle e gestão são apetrechos muito utilizados por empresas em todo mundo, tendo por objetivo fundamental aprimorar os processos, assegurar melhores desempenhos e diminuir, ou até mesmo anular, a ocorrência de erros em determinadas funções. São também usadas para gerir as informações de forma mais prática e exata, sendo, também, bastante úteis aos processos de tomadas de decisões e busca por melhores resultados. Há diversos tipos de ferramentas e, com o avanço contínuo de novas tecnologias, essa variedade só tende a aumentar. Dessa maneira, em virtude de tais necessidades e demandas do mercado, deve-se estar atento ao avanço tecnológico; acompanhar esse mercado também é primordial.

O uso de boas ferramentas de controle e gestão contribui de maneira significativa com os processos e gestões de maior qualidade dentro das organizações, pois, com a aplicação e uso adequado dessas ferramentas, é alcançada uma padronização eficaz e de excelência dentro das companhias (CARPINETTI, 2010). Portanto, fica evidente que é imprescindível utilizar destes mecanismos para se obter praticidade, boa organização e, principalmente, alta qualidade no que é operado. Conforme explica Juran (2009), o apreço pela qualidade decai sobre todas as partes da empresa, desde os processos operacionais até ao desenvolvimento de boas gestões, logo, obtendo-se controle e um ambiente plenamente organizado, os objetivos ficam mais claros e são mais facilmente alcançados.

\subsubsection{SISTEMA DE INFORMAÇÃO}

Com o avanço tecnológico que o mundo presencia e com evolução constante, o uso de sistemas de informações exerce cada vez mais importância dentro das empresas. Estes, geralmente, são softwares que proporcionam maior segurança, gestão e controle de dados, gerando benefícios imprescindíveis que qualquer entidade precisa e não pode renunciar a ter. Sem dúvidas, a ferramenta de maior poder que uma empresa pode ter é a informação, porém, somente tê-la não é o suficiente. 
Saber interpretá-la e usá-la de forma correta é crucial, sendo assim, investir em um sistema de informação que supra as necessidades da organização nunca será um investimento desnecessário, muito pelo contrário, isso pode trazer benefícios inimagináveis e diminuição de custos para entidade, pois esses sistemas fornecem controle e manuseio dos dados com alta qualidade.

Possuir e usar as informações de forma adequada, tomando os devidos cuidados, poderá definir a capacidade e velocidade da organização no momento das tomadas de decisões. Conforme explica Mello (2021), a possibilidade de desenvolver informações e ajustá-las de forma lógica proporciona para as organizações dados relevantes e benefícios inimagináveis, pois permite localizar os gargalos presentes nos processos, ajudando-as a terem uma visão mais clara e com maior capacidade de melhoria, fomentando melhores resultados e diminuindo custos. Dessa forma, o uso de sistemas de informação proporciona maior controle interno para a companhia, tornando-a mais organizada, sendo que isso reflete significativamente no desempenho da organização.

Conforme detalham Maciel e Lima (2011), devido à alta competitividade massiva do mundo empresarial atual, não ter ou usar um sistema de informação eficaz é inconcebível, pois tal ferramenta é primordial para o aperfeiçoamento dos processos e cruciais nos momentos de decisões.

\subsubsection{CONTROLE DE CUSTOS}

Provavelmente, as questões que envolvem os custos sejam o que mais importa dentro de uma empresa, pois estão inteiramente ligadas ao poder financeiro da organização. Para se produzir ou dar qualquer passo, é necessário usar os recursos que a companhia possui. Entretanto, usar tais recursos de forma adequada e alcançar retorno positivo nem sempre acontece na prática, sendo assim, estar a par dos custos envolvendo a organização é primordial. Possuir um bom controle de custos, que é separar e agrupar as saídas de forma condizente, principalmente dentro das Micro e Pequenas empresas, é algo fundamental, pois, dessa forma, fica 
mais claro saber como estão sendo usados os recursos financeiros da entidade, pois, mapeando esses gastos de forma mais lisa, pode-se reduzir custos desnecessários, logo, aumenta-se o faturamento, consequentemente.

Segundo Megliorini (2011), uma forma de entender os custos é classificando-os, pois, diferenciando cada um, pode-se definir suas finalidades e suas devidas apurações. Esses custos podem, nesse contexto, ser classificados como Custos Fixos ou Variáveis. Ainda segundo Megliorini (2011), custos fixos são aqueles custos que, independentemente da quantidade produzida, sempre estarão lá. Já os Custos Variáveis, segundo Schier (2013), são os custos que, conforme o nome sugere, variam de acordo com a quantidade produzida, ou seja, se produzir mais, o custo aumenta, entretanto, se produzir menos, ele diminui. Além de saber sobre Custos Fixos e Variáveis, é importante ressaltar que há outros diversos tipos de custos, tais como os Custos Diretos, Indiretos, Separação de Custos e Despesas, dentre outros.

Portanto, entender os custos realizados dentro da empresa é primordial, pois, dominando isso, é alcançado um maior controle financeiro, além de prover maior estabilidade e segurança para a organização, como, também, maior percepção de visão de futuro.

\subsubsection{CONTROLE FINANCEIRO}

O Controle Financeiro nada mais é do que o espelho da real situação financeira da empresa e de como os recursos estão sendo utilizados. É com os dados desse controle que é possível saber se a empresa está indo bem ou mal, por exemplo. Geralmente, as informações financeiras vêm do patrimônio da instituição ou, sendo mais exato, da apuração dos caixas e do seu fluxo. As contas a pagar e receber correspondem ao registro das entradas e saídas de caixa, sendo, basicamente, a observação e análise desse processo que inicia o controle. Além disso, o controle bancário e do estoque, por exemplo, são pontos chaves para esse monitoramento, também. Conforme ressaltado no início deste artigo, o Sebrae (2013) realizou um estudo e apurou que $25 \%$ das pequenas empresas falecem antes de fazerem seu 
primeiro aniversário e $60 \%$ fecham as portas antes dos 4 anos. Isso acontece por indiferentes fatores, porém, dentre eles, está assertivamente a falta de controle financeiro e o despreparo perante a isso.

Possuir um bom controle financeiro é primordial para se ter uma boa rentabilidade ao final de um período, pois, segundo a pesquisa de Sandana (2013), na realidade empresarial que o mundo vivencia atualmente, deter um bom controle em finanças é fundamental, pois, mesmo que a empresa tenha um bom sucesso em vendas, nada fará muito sentido se seu processo até chegar a isso tenha sido a base de custos elevados de produção. Sendo assim, nem sempre um grande faturamento será sinônimo de rentabilidade. Portanto, para se possuir um controle financeiro eficiente, basta, aos operadores dessa função, identificar e coletar as informações das finanças da companhia, usando-as de forma adequada. Em tempos de crise, Seleme (2010) indica que haja mudanças de costumes e hábitos dentro da organização, com o intuito prover melhor gestão financeira sempre que necessário, além do uso de ferramentas de controle para aprimoramento dos dados existentes, colaborando, assim, para um melhor manuseio das informações geradas.

\subsubsection{PLANEJAMENTO FINANCEIRO}

O planejamento financeiro, como o nome sugere, é uma antecipação para uma meta futura dentro de uma empresa. Isso ocorre para dar mais segurança e pé no chão para o empresário. Saber dos recursos existentes e planejar o uso adequado dele é necessário para não ter possíveis surpresas desagradáveis no futuro. Possuir um bom planejamento financeiro está bastante ligado ao fluxo de caixa, pois manter em mente as dívidas da empresa e um sólido plano contábil para pagá-las é um dos benefícios desse tipo de gestão. Antes de se promover um planejamento financeiro, Lele (2012) explica que, para se obter progresso dentro da empresa, o planejamento precisa ter ciência da realidade patrimonial da organização, cujas metas, ou qualquer ideia que seja proposta, precisam corresponder às metas alcançáveis, ou seja, deve-se localizar a origem dos recursos, os custos e as receitas geradas pela organização, a fim de compará-las e planejar as necessidades do presente, assim 
como as necessidades futuras, sabendo de antemão se os pagamentos destas serão realmente possíveis.

Ao contrário do que muitos possam imaginar, menciona-se, considerando o contexto apresentado, que as empresas de pequeno porte sofrem muito mais riscos econômicos do que as empresas de grande porte. Isso ocorre devido às pequenas possuírem um patrimônio menor, logo, suas disponibilidades de recursos são inferiores. Dessa maneira, estar com um planejamento financeiro em dia é crucial. Segundo Oliveira (2012), possuir um planejamento financeiro está atrelado com os desejos de sucesso para o futuro, sendo que isso pode ser imaginado tanto para o curto quanto para o longo prazo. Tal planejamento visa auxiliar os líderes de forma assertiva nas tomadas de decisões. Por fim, fica evidente que o planejamento financeiro é uma ferramenta de gestão essencial e prioritária, pois dispõe de informações úteis para um desenvolvimento de crescimento mais claro e próximo do sucesso.

\subsection{RESULTADOS ESPERADOS COM O USO DA CONTROLADORIA NAS MPE'S}

Como dito no texto, a Controladoria é uma ferramenta disponível para as empresas que têm o interesse em melhorar seus controles internos e externos. Sabe-se que ter e gerenciar uma empresa no Brasil não é uma questão fácil de ser resolvida, entretanto, a Controladoria serve como apetrecho para solucionar essas dificuldades. A Controladoria pode ser afirmada como uma validação de que a empresa esteja seguindo um caminho correto para a conquista dos seus objetivos, melhorando seus resultados e tornando-a mais eficiente. Espera-se, também, que, com o uso dessa ferramenta (Controladoria), haja unificação entre as gestões empresariais internas e que um bom desempenho seja alcançado, além de uma sólida construção organizacional dentro da companhia (DE PAULLA, 2017).

Os resultados obtidos com uso da Controladoria podem ser diversos, conforme explicam Torricelli e Torricelli (2021). Os autores apontam também que o uso das 
ferramentas de Controladoria exerce um papel fundamental no zelo patrimonial de uma empresa, pois reduzem as suas incertezas e seus riscos. Seu uso (da Controladoria) auxilia de maneira significativa nos controles financeiros e, com o uso adequado, promove-se uma melhor gestão e equilíbrio organizacional, além de melhor segurança e certezas positivas para o futuro. Sendo assim, conforme as palavras dos autores, são estes os resultados e muitos outros que a Controladoria visa proporcionar para as Micro e Pequenas Empresas, a fim de que possam sobreviver ao mercado, mas não somente isso: a ferramenta fornece subsídios para que possa crescer e se destacar em seu ambiente empresarial.

\section{MATERIAIS E MÉTODOS}

\subsection{PROCEDIMENTOS METODOLÓGICOS}

Neste projeto, foi utilizado o método de pesquisa bibliográfica, sendo que, segundo Marconi e Lakatos (2017), a pesquisa bibliográfica é uma apuração com base em materiais já publicados. Essa coleta de dados pode ser feita junto aos livros, revistas, jornais ou qualquer outro tipo de mídia existente. Seu objetivo é fazer com que o pesquisador tenha um norte inicial sobre o que almeja pesquisar, ajudando-o a ter uma noção mais clara e efetiva sobre os conhecimentos que deseja produzir ou estipular. Este mecanismo é primordial para qualquer tipo de pesquisa.

De acordo com Andrade (2017), a pesquisa é um conglomerado de técnicas perfeitamente organizadas. Tem como base o raciocínio lógico, com a proposta de alcançar respostas para questões não solucionadas, atreladas, sempre, aos embasamentos científicos. Diante dessas informações, este artigo utilizou-se dessas ferramentas teóricas, buscando adquirir conhecimento sobre as principais informações sobre o tema Controladoria aplicada às Micro e Pequenas empresas como ferramenta de gestão. 


\subsubsection{QUANTO À NATUREZA}

Quanto à natureza da pesquisa deste artigo, apoiou-se na pesquisa chamada "pura", que também pode ser dita como pesquisa "básica", como aponta Appolinário (2011). A pesquisa "básica" é a evolução do conhecimento sem a necessidade de aplicação da informação discutida ou apurada, com o intuito apenas de rediscutir sobre um conteúdo existente. Dessa maneira, entende-se que a pesquisa "básica" ou pura é uma revisão de algo já publicado e, conforme Gil (2019), a pesquisa "básica" é um tipo de pesquisa que seleciona e agrupa os conhecimentos com o intuito de revisar e proporcionar novas soluções para problemas ainda em evidência.

\subsubsection{QUANTO AOS FINS}

O entendimento dos objetivos deste artigo foi feito a partir de uma pesquisa descritiva. Moseri (2013) exemplifica a pesquisa descritiva da seguinte forma: a pesquisa descritiva mostra particularidades de um determinado objeto ou informação, sendo que se pode verificar similaridade entre dois ou mais objetos ou informação, podendo apontar ou definir sua origem. A pesquisa descritiva não se compromete em comprovar seus levantamentos, entretanto, suas pontuações podem servir como opinião e complementação do assunto discutido. Este tipo de pesquisa, como o próprio nome sugere, busca descrever aquilo que está sendo analisado. Este tipo de método também pode ser chamado de investigativo, pois, geralmente, as pesquisas buscam embasamentos em opiniões, culturas, valores e crenças, por exemplo. Dispõe-se a verificar particularidades das informações encontradas e suas similaridades (MEDEIROS, 2019).

\subsubsection{QUANTO AOS MEIOS}

Esta pesquisa utilizou-se de mecanismos que promoveram as consultas bibliográficas. Foram utilizadas as técnicas de análise de materiais ou documentos. Isso ocorreu por meio de revisão, leitura e interpretação de conteúdos textuais, portanto, buscou-se pelas informações coerentes para desenvolver materiais sobre 
o tema. A análise de materiais e documental é, conforme explica Sá Silva, Almeida e Guindani (2009), uma ferramenta utilizada e promove, dentre outras possibilidades, várias maneiras para compreender, analisar e averiguar determinado documento, a fim de comprovar a sua verdade. Sendo assim, o pesquisador precisa analisar os materiais e documentos encontrados, a fim de verificar se o conteúdo em questão é cabível para complementação do da sua pesquisa ou não, testando as possibilidades (BRANDÃO et al., 2021).

\section{CONSIDERAÇÕES FINAIS}

A partir desta pesquisa, pôde-se demonstrar que as Micro e Pequenas empresas são importantes para a economia brasileira, além disso, ficou claro que elas também são pioneiras em empregabilidade e distribuição de renda. Entretanto, suas dificuldades evidenciadas foram diversas, advindas de diferentes setores e situações. Vale ressaltar que as MPEs, por fazerem parte de um mercado que está em constante evolução, também mudam e se tornam novas com o decorrer do tempo. Por isso, esta pesquisa não é definitiva e visa complementar o assunto, com o objetivo de agregar valor e contribuir para novas pesquisas futuras.

A questão norteadora respondida nesta pesquisa foi: a controladoria pode ser usada como uma ferramenta de gestão para melhorar o desempenho econômico das MPEs? Para respondê-la, foi demonstrado que o uso da controladoria como ferramenta de gestão pode ser muito benéfico e eficaz na busca por soluções eficientes, pois, por unir conhecimentos, tanto em contabilidade quanto em administração, o aplicador dessa ferramenta (Controller) consegue enxergar a empresa de forma mais aprofundada e clara, criando relatórios, identificando as origens dos problemas e, por meio disso, apresenta novos métodos de resolução.

Como mencionado ao longo desta pesquisa, os resultados obtidos evidenciaram a importância da controladoria dentro das MPEs, demonstrando que seus conhecimentos corroboram significativamente para o alcance e maximização de 
seus resultados, fornecendo informações precisas, tempestivas e oportunas que auxiliam os líderes nas tomadas de decisões.

Destacou-se, também, como aspecto relevante, a atuação da controladoria nas fases de planejamento, execução, controle dos processos e de resultados. Além disso, constatou-se que a controladoria possui uma visão geral acerca dos processos inerentes à empresa, pois pode ser útil ao reunir dados de cada setor da companhia, fornecendo relatórios que atendam às necessidades de seus usuários. Dessa maneira, esta pesquisa visa ter importância junto a outras semelhantes já publicadas, sendo mais um material sobre o assunto voltado não apenas para alunos da área da Contabilidade, mas para todos que acharem este conteúdo pertinente. $\mathrm{O}$ assunto que envolve as Micro e Pequenas Empresas no Brasil é de grande importância, pois afeta as questões econômicas que englobam toda a sociedade no país. Sendo assim, espera-se que esse material seja útil e complementar aos demais, colaborando para o surgimento de novas ideias e evolução do conteúdo.

\section{REFERÊNCIAS}

ANDRADE, M. M. de. Introdução à Metodologia do Trabalho Científico. $10^{\mathrm{a}} \mathrm{ed}$. São Paulo: Atlas, 2017.

APPOLINÁRIO, F. Dicionário de Metodologia Científica. $2^{\underline{a}}$ ed. São Paulo: Atlas, 2011. 295p.

BRACHT, D. E.; WERLANG, N. B. Competências empreendedoras: uma investigação com produtores rurais catarinenses. Revista de Empreendedorismo e Gestão de Pequenas Empresas. v. 4, n. 1, p. 101-124, 2015.

BRASIL. Lei Complementar № 123, de 14 de dezembro de 2006. Institui o Estatuto Nacional da Microempresa e da Empresa de Pequeno Porte e dá outras providências. Diário Oficial [da] República Federativa do Brasil, Brasília, DF, 15 dez. 2006. Disponível em: http://www.planalto.gov.br. Acesso em: 30 ago. 2021.

RC: 100868

Link de acesso:

https://www.nucleodoconhecimento.com.br/contabilidade/controladoria 
CARPINETTI, L. C. R. Gestão da Qualidade: conceitos e técnicas. $1^{a}$ ed. São Paulo: Editora Atlas, 2010.

CARPINETTI, L. C. R.; MIGUEL, P. A. C.; GEROLAMO, M. C. Gestão da Qualidade ISO 9001:2008. 2ª ed. São Paulo: Editora Atlas, 2008.

DOLABELA, F. A corda e o sonho. Revista HSM Management, v. 80, pp. 128-132. 2010.

DE PAULA, G, B. Controladoria nas empresas: funções, estrutura e importância. Portal Treasy, 2017. Disponível em: https://www.treasy.com.br/blog/controladorianas-empresas/. Acessado em: 13 jun. 2021.

FORTES, C. C. S; SILVA, D. Controladoria em uma empresa de prestação de serviços contábeis: um caso no município de Lajeado - RS. La Salle Estrela Revista Digital. Rio Grande do Sul, 2016. Pag. 2. Disponível em: https://www.unilasalle.edu.br/uploads/files/8ac6c0ed1b5cec08469a79c6f99d79e1.pd. Acesso em: 07 jun. 2021.

GIL, A. C. Como elaborar projetos de pesquisa. 6aㅡ ed. São Paulo: Atlas, 2019.

KUMAR, S.; ALI, J. Indian agri-seed industry: understanding the entrepreneurial process. Journal of Small Business and Enterprise Development, v. 17, n. 3, p. 455-474, 2010.

LIMA JUNIOR, E. B. et al. Análise documental como percurso metodológico na pesquisa qualitativa. Cadernos da FUCAMP, v. 20, n. 44, 2021.

JURAN, J.M. Qualidade desde o projeto: novos passos para o planejamento da qualidade em produtos e serviços. São Paulo: CENGAGE LEARNING, 2009.

LUZ, E. E. Controladoria Corporativa. Curitiba: Intersaberes, 2014. 
MACIEL, L. F.; LIMA, R. A. O perfil ideal do controller nas condições que se apresentam o mercado de trabalho no Brasil. In: Encontro Latino-Americano de Pós-Graduação, São José dos Campos, SP, Brasil, v. 11, 2011.

MARCONI, M. de. A.; LAKATOS, E. M. Fundamentos de metodologia científica. 8ª ed. São Paulo: Editora Atlas, 2017.

MEDEIROS, J. B. Redação Científica: prática de fichamentos, resumos, resenhas. 13ํㅡㄹ ed. São Paulo: Altas, 2019.

MEGLIORINI, E. Custos: análise e gestão. $3^{\text {a }}$ ed. São Paulo: Pearson Prentice Hall, 2011.

MELLO, A. A importância dos sistemas de informação nas empresas. Brasília, 2021, Universidade Católica de Brasília - UCB. Disponível em: https://ead.catolica.edu.br/blog/importancia-sistemas-de-informacao-nas-empresas. Acesso em: 13 jun. 2021.

MORESI, E. Metodologia da Pesquisa. 2003. Disponível em: http://www.inf.ufes.br/ pdcosta/ensino/2010-2-metodologia-depesquisa/MetodologiaPesquisa-Moresi2003.pdf. Acesso em: 01 nov. 2021.

MÜLER, E. T. C.; BEUREN, I. M. Estrutura formal e práticas da controladoria em empresas familiares brasileiras. Gestão \& Regionalidade, v. 26, n. 76, p. 105-120, 2010.

NASCIMENTO, A. M.; REGINATO, L. Controladoria: um enfoque na eficácia organizacional. 3를. ed. São Paulo: Atlas, 2013.

OLIVEIRA, L. M. de.; PEREZ JR., J. H.; SILVA, C. A. dos. S. Controladoria Estratégica. Textos e casos práticos com solução. $8^{\underline{a}}$ ed. São Paulo: Altas, 2011.

PEREZ JR., J.H.; OLIVEIRA, L.M.; COSTA, R.G. Gestão estratégica de custos: textos e teste com resposta. $7^{a}$ ed. São Paulo: Atlas, 2011.

RC: 100868

Link de acesso:

https://www.nucleodoconhecimento.com.br/contabilidade/controladoria 
PORTAL DA INDÚSTRIA. Qual a definição de Micro e pequena empresa? 2021. Disponível em: http://www.portaldaindustria.com.br/industria-de-a-z/micro-e-pequena empresa/\#: :text=Micro\%20empresa\%3A\%20empresa\%20que\%20t\%C3\%AAm,a\% 2099\%20pessoas\%20na\%20ind\%C3\%BAstria. Acesso em: 30 ago. 2021.

SCHMIDT, P.; SANTOS, J. L. dos.; MARTINS, M. A. dos. Santos. Manual de Controladoria. São Paulo: Atlas, 2014.

SCHIER, C. U. da. C. Gestão de custos. Curitiba: Editora Ibpex, 2006.

SERVIÇO BRASILEIRO DE APOIO ÀS MICRO E PEQUENAS EMPRESAS SEBRAE. Micro e pequenas empresas geram 27\% do PIB do Brasil. Disponível em: https://www.sebrae.com.br/sites/PortalSebrae/ufs/mt/noticias/micro-e-pequenasempresas-geram-27-do-pib-do brasil,ad0fc70646467410VgnVCM2000003c74010Arcrd. Acesso em: 12 mai. 2021.

SOARES, P. A. et al. Santa Maria, Metodologia da pesquisa científica. $1^{\text {a }}$ ed. Santa Maria: UFSM, NTE, 2018.

SOUZA, L. C. Controladoria aplicada aos pequenos negócios. $1^{\underline{a}}$ ed. 2. reimpr. Curitiba: Juruá, 2010.

SEBRAE. Sobrevivência das empresas no Brasil. 2016. 68 f. Disponível em: http://datasebrae.com.br/wp-content/uploads/2017/04/Sobreviv\%C3\%AAncia-deEmpresas-no-Brasil-2016-FINAL.pdf. Acesso em: 03 ago. 2021.

TORRICELLI, H.; TORRICELLI, T. V. C. G. A Importância da Controladoria nas pequenas empresas. Revista Científica Multidisciplinar Núcleo do Conhecimento, Ano 06, v. 5, n. 5, pp. 174-190, 2021.

Enviado: Setembro, 2021.

Aprovado: Novembro, 2021. 